\title{
Innovation in E-Commerce Platform Development Based on Salam Agreement Using Platform Design Toolkit
}

\author{
Nadya Fira Efendi ${ }^{1}$, M. Ruslianor Maika ${ }^{2}$ \\ mr.maika@umsida.ac.id \\ Universitas Muhammadiyah Sidoarjo, Sidoarjo, Indonesia ${ }^{1,2}$
}

\begin{abstract}
The rapid development of e-commerce has become an opportunity in optimizing the implementation of sharia business models by innovating the development of ecommerce platform based on regards to using mapping platform design toolkit. Research and development research methods through the stages of product sprint design development that aims to design, test, evaluate and develop the research object under study. The results of the development show that 3 out of 9 components of the platform design toolkit require special attention in mapping the innovation of e-commerce platform development based on greetings, namely transactions (submitting orders, greeting agreements, online payments, submitting transaction evidence, order provisioning, order development transparency, order delivery, cancellation / return of orders), services (order specifications, dashboard order development, sales margins, valid transactions, transaction assessments, proof of orders), value propositions (greetings agreement, transaction ridho bi ridho). Conducting online transactions through order-based agreements to provide guaranteed quality of goods for buyers and working capital for sellers so that they are able to create mutual benefits for sellers and buyers through buying and selling good (good and blessed).
\end{abstract}

Keywords: E-Commerce, Akad Salam, Platform Design Toolkit..

\section{Pendahuluan}

Pesatnya perkembangan internet memunculkan inovasi konsep dan praktik dalam perdagangan secara elektronik atau disebut dengan e-commerce.[1] E-commerce merupakan media belanja online konsumen menggunakan sebuah platform yang terkoneksi internet untuk menelusuri, membeli, dan membayar barang yang diinginkan. Melalui perdagangan elektronik atau e-commerce bisnis dapat menjangkau pelanggan dengan cara yang lebih efisien dengan menawarkan lebih banyak informasi, opsi, personalisasi, dan kenyamanan dalam bertransaksi. E-commerce juga memberikan peluang besar bagi bisnis untuk mencapai pasar yang tidak dapat dijangkau.[2]

Data resmi tentang transaksi e-commerce dalam laporan ekonomi yang dipaparkan oleh United Nations Conference on Trade and Development (UNCTAD) menyebutkan bahwa nilai total transaksi e-commerce secara global, baik domestik ataupun lintas-batas adalah sebesar US \$ 16 triliun pada tahun 2013 dan mengalami peningkatan sebanyak 56\% dengan total transaksi sebesar US \$ 25 triliun pada tahun 2015. United States International Trade Commission (USITC) memperkirakan besarnya transaksi business-to-business (B2B) pada tahun 2016 
sebesar US\$23,9 triliun enam kali lebih besar dari transaksi business-to-consumer (B2C) yang berjumlah US $\$ 3,8$ triliun.[3]

Adanya kemiripan antara transaksi perdagangan elektronik atau e-commerce dan bai salam seperti halnya kesepakatan antara pembeli dan penjual melalui sebuah kata-kata atau istilah atau tulisan yang dipahami kedua belah pihak, mayoritas pembayaran yang dilakukan dimuka merupakan salah satu rukun bai salam menjadikan konsep e-commerce dapat diterima dalam masyarakat muslim. Meski terdapat beberapa perbedaan isu mengenai pembelian online ataupun e-pay menjadikan tantangan baru yang mengharuskan para cendekiawan dan peneliti Islam untuk memperluas cakupan definisi di luar konteks tradisional.[4]

Bai salam atau akad salam menurut Accounting and Auditing Organization For Islamic Financial Institutions (AAOIFI) merupakan skema jual beli barang dengan cara pesanan, yakni pembayaran dilakukan dimuka dengan syarat dan ketentuan tertentu yang disepakati semua pihak yang terkait kemudian barang diproses sesuai pesanan dan diserahkan nanti pada waktu dan tempat yang telah disepakati.[5] Bai salam atau Akad salam digunakan untuk memfasilitasi kebutuhan produsen sebagai penyedia modal kerja. Implementasi bai salam atau akad salam memberikan keuntungan terhadap pihak lembaga pembiayaan atau pembeli yang mendapatkan barang dengan harga yang relatif lebih murah. Sebaliknya, penjual atau produsen akan mendapatkan harga di awal untuk kebutuhan produksi. Sehingga konsep akad salam yang merupakan budaya gotong royong dapat memudahkan kebutuhan manusia dalam menjalankan roda perekonomian.[6]

Data Otoritas Jasa Keuangan per Juni 2018 menunjukan jenis pembiayaan yang diberikan Bank Umum Syariah dan Unit Usaha Syariah didominasi oleh pembiayaan murabahah sebesar $51,99 \%$ dari total keseluruhan komposisi pembiayaan sebesar 281,210 Triliun, sedangkan untuk pembiayaan yang menggunakan akad salam sebesar 0,00 \%.[7] Padahal, jenis akad salam maupun salam paralel yang dilegalisasikan OJK untuk pihak Perbankan Syariah dapat diimplementasikan terhadap sektor riil yang ada khususnya pada sektor pertanian.[8]

Berdasarkan pesatnya potensi e-commerce dan rendahnya peranan perbankan dalam pembiayaan menggunakan akad salam[9], menjadi dasar peneliti dalam melakukan inovasi pengembangan platform e-commerce yang berbasis akad salam dengan menggunakan Framework Platform Design Toolkit.

Platform Design Toolkit merupakan sebuah konsep pembaharuan modifikasi dari Business Model Canvas (BMC) yang diciptakan oleh Simone Cirero pada tahun 2013 yang memiliki sembilan komponen yaitu platform owner, platform stakeholders, peers, partners, transactions, channel and context, services, value propositions, infrastructure and core components. Tujuan penggunaan Framework Platform Design Toolkit agar peneliti dapat melihat banyak perspektif dan pembaharuan dalam sebuah bisnis dengan memetakan komponen model bisnis platform ecommerce berbasis akad salam.[10]

\section{Metode}

Metode penelitian menggunakan tahapan teori design sprint yang bertujuan untuk merancang, menguji, mengevaluasi dan mengembangkan objek penelitian yang diteliti. Design sprint menjelaskan tahapan-tahapan untuk memulai dan mendapatkan validasi awal dalam menciptakan atau mengembangkan sebuah produk, terlihat pada Gambar 1 [11]. 


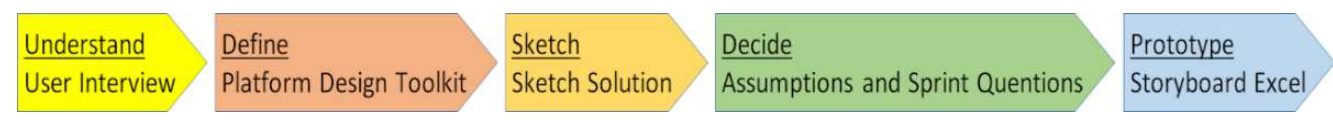

Gambar 1 Bagan Prosedur Pengembangan Penelitian

1. Understand - Maping Experience

Maping experience adalah metode user experience yang memetakan langkah demi langkah pengalaman yang dimiliki pengguna tertentu dalam ruang masalah atau konteks platform ecommerce untuk membangun empati pengembangan dengan motivasi, kebutuhan, dan poin keluhan pengguna.

Maping experience sangat membantu untuk mengembangkan produk baru, atau mencari peluang produk yang sudah ada untuk ditingkatkan. Pada tahapan ini peneliti akan memetakan poin penting pengalaman pengguna berdasarkan kuesioner yang dibagikan kepada beberapa pengguna platform e-commerce.

2. Define - Platform Design Toolkit

Tahapan definisi dilakukan setelah memahami konsep penelitian berdasarkan maping experience pada tahap sebelumnya, dengan mendefinisikannya ke dalam 9 komponen yang terdapat dalam platform design toolkit yaitu platform owner, platform stakeholders, peers, partners, transactions, channel and context, services, value propositions, infrastructure and core components untuk membangun fokus yang spesifik dalam pengembangan platform e-commerce berbasis akad salam.

3. Sketch - Sketch Solution

Pada tahapan ini, peneliti memetakan sketsa solusi dalam bentuk pembaruan platform design toolkit berdasarkan penelitian platform e-commerce. Tujuannya adalah untuk menciptakan satu gagasan yang sepenuhnya sempurna untuk solusi yang dianggap sebagai yang terbaik. Sketsa Solusi harus mencakup tiga bingkai atau keadaan konsep untuk membantu menggambarkan cara kerjanya, serta judul yang jelas untuk membantu orang mengingatnya.

4. Decide - Present Solution Sketches

Pada tahap ini, peneliti akan melakukan sharing sesson dengan membuat sebuah tim belajar dan setiap anggota tim mempresentasikan sketsa solusi mereka dan mendiskusikan berbagai fitur konsep. Ini memberikan kesempatan bagi tim untuk mendapatkan pemahaman yang lebih baik tentang solusi yang dimaksudkan dan memisahkan perbedaan dari ide-ide yang serupa.

5. Prototype - Storyboard Excel

Pada fase Prototipe, peneliti akan memetakan sketsa solusi inovasi pengembangan dari platform e-commerce berbasis akad salam dalam bentuk microsoft excel. Perancangan prototipe berbentuk microsoft excel oleh peneliti bertujuan untuk membuat prototipe yang cukup nyata agar mudah divalidasi. Prototipe digunakan sebagai percobaan untuk menguji hipotesis, sehingga pada tahapan ini peneliti harus berpikir kritis tentang apa yang akan peneliti bangun untuk mendapatkan umpan balik yang peneliti butuhkan untuk memvalidasi ataupun membatalkan hipotesis.

\section{Pembahasan}

Platform e-commerce merupakan lapak perdagangan online yang mempertemukan antara penjual dan pembeli secara online. Sebuah bisnis harus memperhatikan model bisnisnya terlebih 
dahulu sama halnya dengan platform, harus mendesign platform terlebih dahulu sehingga dapat mengetahui value dan jenis akad apa yang harus diimplementasikan sesuai dengan nilai kepatuhan syariah.

E-Commerce memiliki beberapa kategori model bisnis berdasarkan segmentasi pasar dan mayoritas yang diterapkan di Indonesia diantaranya : [12]

a. Business to Business (B2B) didefinisikan sebagai kegiatan kolaboratif untuk memanfaatkan barang dan jasa yang tidak digunakan atau tidak optimal yang dimiliki secara individual oleh perusahaan untuk perusahaan lain.

b. Business to Customer (B2C) didefinisikan sebagai aktivitas yang dilakukan produsen kepada konsumen secara langsung.

c. Customer to Customer (C2C) didefiniskan sebagai aktivitas bisnis (penjualan) yang dilakukan oleh individu (konsumen) kepada individu (konsumen) lainnya.

d. Customer to Business (C2B) didefinisikan sebagai aktivitas bisnis (penjualan) yang dilakukan oleh individu (konsumen) kepada produsen.

Implementasi akad salam sangat sesuai dengan kategori model bisnis platform B2C. Aspek penting $\mathrm{B} 2 \mathrm{C}$ adalah pemahaman perilaku pembelian online konsumen dari tahap awal hingga pasca penerimaan. Sama halnya dengan akad salam, Muslam ilaihi (penjual) wajib menyerahkan muslam fiih (barang/objek) kepada muslaim (pembeli) ketika tempo yang diperjanjikan tiba dan barang tersebut harus sesuai dengan sifat dan ukuran yang telah ditetapkan dalam akad. Pembeli berkewajiban menerimanya jika cocok dengan spesifikasinya dan berhak menolak jika tidak cocok dengan spesifikasinya yang dijelaskan dalam akad.

Berikut inovasi design pengembangan platform e-commerce berbasis akad salam menggunakan platform design toolkit:

1. Platform Owners

Platform Owners merupakan "pemilik" platform yang memiliki visi di balik terealisasinya pasar dan bertanggung jawab untuk memastikan bahwa platform selalu melakukan kegiatan produktif.

\begin{tabular}{|c|cc|}
\hline No & Tabel 1. Platform Owner \\
\hline 1. & Perseroan Terbatas (PT) & Platform owner \\
\hline
\end{tabular}

2. Platform Stakeholders

Kategori ini, mencakup aktor-aktor publik yang berurusan dengan regulasi dan kontroling platform pada basis lokal merupakan perwakilan dari pluralitas rekan dan mitra yang terlibat dalam penciptaan value dan membantu berkembangnya platform.

Tabel 2. Platform Stakeholders

\begin{tabular}{|l|l|c|l|}
\hline No & \multicolumn{1}{|c|}{ Platform stakeholder } & Peran & \multicolumn{1}{c|}{ Fungsi } \\
\hline 1. & LAZISWAF & Investor & $\begin{array}{l}\text { Memberikan investasi dalam bentuk dana } \\
\text { wakaf produktif kepada platform owner }\end{array}$ \\
\hline 2. & Otoritas Jasa Keuangan (OJK) & Regulator & $\begin{array}{l}\text { Pembuat kebijakan jasa keuangan berbasis } \\
\text { ecommerce di Indonesia }\end{array}$ \\
\hline
\end{tabular}

3. Peers

Peer adalah individu atau usaha kecil-menengah yang berperilaku sebagai entitas tunggal yang dapat diidentifikasi dengan minat khusus dan tujuan yang dapat diidentifikasi bahwa proposisi nilai platform harus terpenuhi. Terdapat 2 macam peers dalam platform design toolkit yaitu:

a. Peers Producers

Peer Producers (PP) dapat disebut produsen atau provider adalah entitas yang memberikan value pada sisi suplai ekosistem pasar menjadi peluang untuk 
meningkatkan profesionalitas dan mengasah kemampuan menuju kinerja yang lebih baik.

Tabel 3. Peers Producers

\begin{tabular}{|c|cc|}
\hline No & \multicolumn{1}{c|}{ Peers Producers } \\
\hline 1. & Penjual \\
\hline \multicolumn{3}{|c|}{ b. Peers Consumers } \\
& Peer Consumers (PC) dapat disebut pengguna, adalah entitas yang tertarik dalam \\
& mengkonsumsi, memanfaatkan, mengakses value yang diciptakan melalui dan pada \\
& platform.
\end{tabular}

4. Partners

Partners (PA) adalah entitas yang berusaha menciptakan value profesional tambahan bukan value utama akan tetapi sangat berhubungan dalam kolaborasi dengan pemilik platform. Peran partner dalam platform memfasilitasi, melayani, dan meningkatkan nilai produksi dengan bertindak sebagai pialang, fasilitator, dan konektor.

Tabel 5. Partners

\begin{tabular}{|c|l|c|l|}
\hline No & \multicolumn{1}{|c|}{ Partners } & Peran & \multicolumn{1}{c|}{ Fungsi } \\
\hline 1. & Agen Pemasaran & $\begin{array}{c}\text { Corporate } \\
\text { Partner }\end{array}$ & $\begin{array}{l}\text { Sebagai mitra perusahaan yang bekerja sama } \\
\text { dalam promosi barang pesanan }\end{array}$ \\
\hline 3. & Social Media & Media Partner & $\begin{array}{l}\text { Memperluas jangkauan pasar platform } \text { - } \\
\text { commerce dengan memberitakan kegiatan } \\
\text { platform tersebut }\end{array}$ \\
\hline 6. & Bank Syariah & $\begin{array}{c}\text { Payment } \\
\text { Partner }\end{array}$ & $\begin{array}{l}\text { Menyediakan virtual account untuk setiap } \\
\text { pemesanan pembeli }\end{array}$ \\
\hline
\end{tabular}

5. Transactions

Transaksi adalah subaksi tempat value diciptakan, diberikan, ditransfer ataupun diperdagangkan antara para entitas. Transaksi tersebut terdiri atas pertukaran atau transfer antara Peer dan Partner melalui platform. Transaksi dapat mencakup pertukaran jasa atau akses sumber daya.

\begin{tabular}{|c|c|c|c|c|}
\hline \multicolumn{5}{|c|}{ Tabel 6. Transactions } \\
\hline No & Transactions & 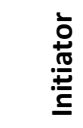 & 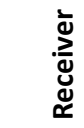 & Currency/Value Unit \\
\hline 1. & Mengadakan Kampanye Produk & $P$ & C & Pengetahuan \\
\hline 2. & Mengajukan Pesanan Produk & C & $P$ & Pengetahuan \\
\hline 3. & Akad Salam & $\mathrm{P}, \mathrm{C}$ & - & Kontrak Tertulis \\
\hline 4. & Transaksi Pembayaran Online & C & $\mathrm{PP}, \mathrm{P}$ & Dana \\
\hline 5. & Penyerahan Bukti Transaksi & $P$ & C & Informasi \\
\hline 6. & Penyediaan Produk Pesanan & $\mathrm{P} / \mathrm{PA}$ & C & Barang \\
\hline 7. & Tranparansi Perkembangan Produk Pesanan & $\mathrm{P}$ & C & Informasi \\
\hline 8. & Penyerahan Produk Pesanan & $\mathrm{P} / \mathrm{PA}$ & C & Barang \\
\hline 9. & Pembatalan / Pengembalian Produk Pesanan & C & $P$ & Barang dan Dana \\
\hline
\end{tabular}

6. Channel and Context 
Channel dan context adalah saluran atau rancangan setiap transaksi yang terjadi dalam konteks formal atau informal untuk mengoptimalkan dan mempermudah transaksi. Ketika transaksi kompleks dipecah menjadi beberapa sub-transaksi, channel dan context harus ada untuk setiap fase agar berjalan lancar dan menciptakan pertukaran pada platform secara produktif.

Tabel 7. Channel and Context

\begin{tabular}{|c|l|}
\hline No & \multicolumn{1}{c|}{ Infrastructure and Core Components } \\
\hline 1. & Website \\
\hline 2. & Email \\
\hline
\end{tabular}

7. Services

Layanan mendukung peningkatan berkelanjutan kinerja peserta dari entitas yang memproduksi dan juga melengkapi pengalaman yang disediakan oleh ekosistem melalui platform yang ditargetkan kepada pelanggan. Terdapat 3 macam services dalam platform design toolkit yaitu :

a. Enabling Services

Layanan yang ditargetkan untuk mendukung partner menghasilkan value dengan mendapatkan pasar baru, mencapai peluang dan visibilitas baru.

\begin{tabular}{|c|c|c|l|}
\multicolumn{4}{|c|}{ Tabel 8. Enabling Services } \\
\hline No & \multicolumn{1}{|c|}{ Enabling Services } & Target Partner & \multicolumn{1}{c|}{ Fungsi } \\
\hline \multirow{2}{*}{1.} & $\begin{array}{l}\text { Pencantuman Logo Partner pada } \\
\text { website platform }\end{array}$ & Media Partner & $\begin{array}{l}\text { Sebagai salah satu bentuk } \\
\text { reward dan kerjasama dengan } \\
\text { partner }\end{array}$ \\
\cline { 3 - 4 } & Corporate Partner & \\
\hline
\end{tabular}

b. Empowering Services

Layanan yang ditargetkan untuk mendukung produser dalam memulai kegiatan transaksi, mengasah kemampuan kinerja dalam platform menjadi lebih baik.

Tabel 9. Empowering Services

\begin{tabular}{|c|l|l|}
\hline No & \multicolumn{1}{|c|}{ Empowering Services } & \multicolumn{1}{c|}{ Fungsi } \\
\hline 1. & Forecasting Price & $\begin{array}{l}\text { Membantu producers dalam menimbang harga dan } \\
\text { menentukkan barang yang akan dipaparkan }\end{array}$ \\
\hline 2. & Option dan Deskripsi Produk & Membantu producers dalam klasifikasi penjualan domba \\
\hline 3. & $\begin{array}{l}\text { Frequently Asked Question } \\
\text { (FAQ) }\end{array}$ & $\begin{array}{l}\text { Efisiensi waktu producers dalam menjawab pertanyaan } \\
\text { yang sering ditanyakan consumer }\end{array}$ \\
\hline 4. & $\begin{array}{l}\text { Dashboard Perkembangan } \\
\text { Produk Pesanan }\end{array}$ & $\begin{array}{l}\text { Membantu producers merapikan laporan dalam } \\
\text { memantau perkembangan domba pesanan consumer }\end{array}$ \\
\hline 5. & Data Pengguna & $\begin{array}{l}\text { Sebagai arsip producers dalam mendokumentasikan } \\
\text { identitas pembeli untuk memberikan informasi terkini } \\
\text { pada pengguna }\end{array}$ \\
\hline 6. & Margin Penjualan & Sebagai pendapatan producers \\
\hline 7. & Valid Transaction & Mempermudah producers dalam pengarsipan transaksi \\
\hline 8. & Penilaian Transaksi & Sebagai acuan pengembangan operasional \\
\hline
\end{tabular}

c. Other Services

Platform menyediakan layanan "pelengkap", yang berorientasi pada kebutuhan konsumen. Melengkapi pertukaran value utilitas pada platform.

Tabel 10. Other Services

\begin{tabular}{|c|l|l|}
\hline No & \multicolumn{1}{|c|}{ Other Services } & \multicolumn{1}{c|}{ Fungsi } \\
\hline 1. & Forecasting Price & $\begin{array}{l}\text { Sebagai layanan consumers untuk membandingkan harga } \\
\text { dan menentukan domba yang akan dibeli }\end{array}$ \\
\hline 2. & Opsi dan Deskripsi Produk & $\begin{array}{l}\text { Sebagai layanan consumers dalam memilih kriteria domba } \\
\text { yang akan dibeli }\end{array}$ \\
\hline
\end{tabular}




\begin{tabular}{|c|l|l|}
\hline 3. & Keranjang Belanja & $\begin{array}{l}\text { Sebagai layanan consumers untuk mengetahui jumlah } \\
\text { pesanan yang dibeli }\end{array}$ \\
\hline 4. & $\begin{array}{l}\text { Frequently Asked Question } \\
\text { (FAQ) }\end{array}$ & $\begin{array}{l}\text { Sebagai layanan panduan bagi consumers berisi mengenai } \\
\text { prosedur pembelian domba }\end{array}$ \\
\hline 5. & $\begin{array}{l}\text { Dashboard Perkembangan } \\
\text { Produk Pesanan }\end{array}$ & $\begin{array}{l}\text { Sebagai layanan consumers dalam memantau } \\
\text { perkembangan domba yang dipesan }\end{array}$ \\
\hline 6. & Live Chat & $\begin{array}{l}\text { Memudahkan consumers dalam berkomunikasi dengan } \\
\text { producers }\end{array}$ \\
\hline 7. & Spesifikasi Produk Pesanan & $\begin{array}{l}\text { Sebagai layanan consumers untuk menentukkan } \\
\text { ketentuan spesifikasi barang sesuai kemampuan produksi, } \\
\text { sehingga memudahkan dalam penyediaan barang pesanan }\end{array}$ \\
\hline 8. & Bukti Pesanan & $\begin{array}{l}\text { Bentuk pertanggungjawaban producer sebagai layanan } \\
\text { untuk consumers }\end{array}$ \\
\hline 9. & Berita Terkini & $\begin{array}{l}\text { Sebagai layanan consumer untuk mendapatkan informasi } \\
\text { terkini meliputi jual beli domba }\end{array}$ \\
\hline 10. & Artikel / Kajian Muamalah & $\begin{array}{l}\text { Sebagai layanan pengetahuan consumer dalam } \\
\text { bermuamalah sesuai syariah }\end{array}$ \\
\hline 11. & Penilaian Transaksi & $\begin{array}{l}\text { Sebagai layanan consumers dalam penilaian kepuasan } \\
\text { pelayanan transaksi terhadap penjual }\end{array}$ \\
\hline 12. & $\begin{array}{l}\text { Pembatalan / Pengembalian } \\
\text { Produk Pesanan }\end{array}$ & $\begin{array}{l}\text { Sebagai layanan consumer apabila domba pesanan tidak } \\
\text { sesuai dengan kesepakatan }\end{array}$ \\
\hline
\end{tabular}

8. Value Propositions

Menciptakan proposisi nilai yang jelas. Platform design toolkit memiliki setidaknya dua proposisi nilai yaitu menuju sisi permintaan dan menuju sisi penawaran. Terdapat 2 macam value proposition yang dirancang dalam platform design toolkit, di antaranya:

a. Core Value Propositions

Merupakan value utama yang ingin dciptakan oleh platform untuk entitas intinya dengan menargetkan Peer Consumers sebagai segmen yang ingin mengonsumsi value. Sebagian besar platform melakukannya dengan cara menargetkan Peer producers dan partner menciptakan volume transaksi lebih rendah dengan nilai transaksi lebih besar.

Tabel 11. Core Value Propositions

\begin{tabular}{|c|l|c|l|}
\hline No & \multicolumn{1}{|c|}{ Core Value Propositions } & Target & \multicolumn{1}{c|}{ Fungsi } \\
\hline 1. & $\begin{array}{l}\text { Akad Salam : Jual beli produk } \\
\text { pesanan aman dan berkah sesuai } \\
\text { dengan spesifikasi yang disepakati } \\
\text { dengan kualitas terbaik dan harga } \\
\text { yang murah }\end{array}$ & Consumer & $\begin{array}{l}\text { Sebagai bentuk daya tarik kepada } \\
\text { consumers agar tertarik untuk } \\
\text { membeli produk di platform }\end{array}$ \\
\cline { 1 - 3 } 2. & $\begin{array}{l}\text { Kenyamanan dan kepuasan dalam } \\
\text { bertransaksi (ridho bi ridho) }\end{array}$ & & \\
\hline
\end{tabular}

b. Ancillary Value Propositions

Merupakan proposisi value tambahan atau value sekunder yang ingin diciptakan oleh platform. Proposisi value tambahan dapat melengkapi proposisi value utama dari sisi permintaan platform dengan satu target ke sisi penawaran.

Tabel 12. Contoh Ancillary Value Propositions

\begin{tabular}{|c|l|c|l|}
\hline No & \multicolumn{1}{|c|}{ Ancillary Value Propositions } & Target & \multicolumn{1}{c|}{ Fungsi } \\
\hline 1. & $\begin{array}{l}\text { Akad Salam : Jual beli produk } \\
\text { pesanan aman dan berkah melalui } \\
\text { pembayaran di awal sebagai modal } \\
\text { produksi }\end{array}$ & Producer & $\begin{array}{l}\text { Sebagai bentuk daya tarik kepada } \\
\text { producers untuk memulai penjualan } \\
\text { melalui platform }\end{array}$ \\
\hline
\end{tabular}




\begin{tabular}{|l|l|c|l|}
\hline 2. & $\begin{array}{l}\text { Peningkatan jumlah traffic pada } \\
\text { media partner yang telah } \\
\text { memberikan informasi mengenai } \\
\text { platform }\end{array}$ & $\begin{array}{l}\text { Media } \\
\text { Partner }\end{array}$ & $\begin{array}{l}\text { Sebagai bentuk reward penghargaan } \\
\text { kepada partner sehingga terjadi } \\
\text { timbal balik dalam bentuk traffic ke } \\
\text { partner mitra }\end{array}$ \\
\hline
\end{tabular}

9. Infrastructure \& Core Components

Infrastruktur dan struktural bahasa asing dikendalikan dan dimiliki oleh pemilik platform dan diatur sesuai dengan tata kelola platform yang memastikan bahwa platform berfungsi dan dapat digunakan oleh ekosistem. Infrastruktur dan struktural bahasa asing dapat berwujud seperti aplikasi atau kantor dan tidak berwujud seperti kesepakatan standarisasi platform.

\begin{tabular}{|c|c|}
\multicolumn{2}{c}{ Tabel 13. Infrastructure and Core Components } \\
\hline No & Infrastructure and Core Components \\
\hline 1. & Website \\
\hline
\end{tabular}

\section{Kesimpulan}

Melakukan transaksi online melalui pesanan berbasis akad salam memberikan jaminan kualitas barang bagi pembeli dan modal kerja bagi penjual. Sehingga mampu menciptakan kemashlahatan bersama bagi penjual dan pembeli melalui jual beli yang mabrur (baik dan berkah).

\section{References}

[1] Adel. A. Alyoubi, "E-commerce in Developing Countries and how to Develop them during the Introduction of Modern Systems," Procedia Comput. Sci., vol. 65, pp. 479-483, 2015, doi: 10.1016/j.procs.2015.09.127.

[2] C. Cottam, "Faculty Sponsor: Dr. Elizabeth Crosby, Department of Marketing," p. 12, 2013.

[3] World Trade Organization, "World Trade Report 2018," 2018.

[4] A. H. A. Mokhtar, M. Z. Muhammad, and T. Amboala, "Bai As-Salam and E-Commerce: A Comparative Analysis From Shariah Perspective," p. 8, 2013.

[5] Accounting and Auditing Organization for Islamic Financial Institutions, AAOIFI Shari'ah Standards. Manama, Kingdom Of Bahrain: King Fahd National Library Cataloging in Publication Data, 2017.

[6] M. R. Maika, "Model Bisnis Pembelian Kolektif (Crowdfunding) Jual Beli Salam (Pesanan) Petani dan Warga Perumahan,” p. 12, 2016.

[7] Otoritas Jasa Keuangan, "Statistik salam SPS Juni 2018," Jakarta, 2018.

[8] Z. Nasution, "Model Pembiayaan Syariah untuk Sektor Pertanian," IQTISHADIA J. Ekon. Perbank. Syariah, vol. 3, no. 2, p. 324, Dec. 2016, doi: 10.19105/iqtishadia.v3i2.1081.

[9] W. F. Ningsih, "Modifikasi Pembiayaan Salam dan Implikasi Perlakuan Akuntansi Salam," J. Akunt. Univ. JEMBER, vol. 13, no. 2, p. 13, Dec. 2015, doi: 10.19184/jauj.v13i2.1567.

[10] The Platform Design Toolkit Team, New Platform Design Toolkit 2.0 UserGuide. 2017.

[11] R. Banfield, C. T. Lombardo, and T. Wax, Design sprint: a practical guidebook for building great digital products. Sebastopol, CA: O’Reilly Media, Inc, 2016.

[12] E. Turban, D. R. King, J. K. Lee, T.-P. Liang, and D. C. Turban, Electronic commerce: a managerial and social networks perspective, Eighth edition, Revised Edition. Cham: Springer, 2015. 